
\title{
3 Research Square \\ The Effect of Epigallocatechin gallate on Cross-talk Between Autophagy and Apoptosis in NALM-6 Cell Line
}

\section{Faezeh Gharehchahi}

Shiraz University of Medical Sciences School of Paramedical Sciences

\section{Farahnaz Zare}

Shiraz University of Medical Sciences School of Paramedical Sciences

\section{Gholamreza Rafie Dehbidi}

Shiraz University of Medical Sciences School of Paramedical Sciences

\section{Zahra Yousefi}

Shahroud University of Medical Sciences

\section{Somayeh Pourpirali}

Islamic Azad University Najafabad Branch

Gholamhossein Tamaddon ( $\nabla$ tamadon@sums.ac.ir)

Shiraz University of Medical Sciences School of Paramedical Sciences https://orcid.org/0000-00018158-6004

\section{Research Article}

Keywords: Acute Lymphoblastic Leukemia, NALM-6, Epigallocatechin Gallate, Apoptosis, Autophagy

Posted Date: December 6th, 2021

DOI: https://doi.org/10.21203/rs.3.rs-1111288/v1

License: (c) (1) This work is licensed under a Creative Commons Attribution 4.0 International License. Read Full License 


\section{Abstract}

Background: Acute lymphoblastic leukemia is a prevalent hematological malignancy in 2-5-year-old children. Chemotherapy, as the most common treatment for ALL, is not usually responsive.

Epigallocatechin gallate (EGCG), a small molecule extracted from green tea, has significant effects on tumor cells through different mechanisms, such as DNA damage, cell cycle arrest, oxidative stress, apoptosis, and autophagy. In this study, we investigated the impact of EGCG on autophagy and apoptosis in NALM-6 cell line.

Methods and results: Cell viability and apoptosis were assessed by MTT and Trypan blue exclusion assay, and flow cytometry. It was shown that EGCG remarkably inhibited proliferation, reduced cell viability, and induced apoptosis in NALM-6 cell line $(P<0.05)$. In addition, real-time PCR and western blot analysis were used to examine autophagy. It was observed that EGCG resulted in a 4-fold increase in LC3 protein level $(P<0.05)$ while reducing the mRNA expression level of $L C 3 B, P 62 / S Q S T M 1$, and Atg2B genes $(P<0.01)$. It also caused around 1.3-fold increase in DRAM1 mRNA expression level $(P<0.05)$. Finally, it was indicated that the inhibition of autophagy affects apoptosis neither in untreated nor treated cells with EGCG.

Conclusion: These results show that EGCG can induce apoptosis and autophagy in NALM- 6 cell line while inhibition of autophagy cannot affect apoptosis in this cell line.

\section{Introduction}

Acute lymphoblastic leukemia (ALL) is a hematological malignancy disorder, involving $B$ or $\mathrm{T}$ lymphoid precursors with various biological and clinical manifestations [1]. Typically, different genetic changes in the lymphoid precursors lead to maturation and differentiation arrest, or excessive proliferation; hence, by creating a clone of immature lymphoid cells in the bone marrow, normal hematopoiesis is suppressed [2]. Precursor B-ALL accounts for approximately $88 \%$ of leukemia cases amongst children [3]. Despite new studies on the use of specific transcription factor inhibitors, immunotherapy, and epigenetic methods, the current treatment modality of ALL is based on the chemotherapy principle, bone marrow transplantation, or CNS prophylaxis through radiation therapy in some cases [4]. Given that there are significant number of cases without any appropriate prognosis and responsiveness to treatment, there is a need to investigate new methods and approaches [2].

Today, it is well known that autophagy and apoptosis play an important role in the physiology and pathophysiology of various diseases such as cancer. Apoptosis or programmed cell death is one of the most crucial modulators in cancer [5]. In addition, autophagy acts as a tumor suppressor, which protects normal cells from genetic damage, oxidative stress, and stem cell proliferation or progenitors associated with malignancy. However, with respect to the cancer stage or patient's therapeutic condition, it can differently affect cancer cells that are heavily stressed by starvation, hypoxia, and chemotherapy or radiotherapy [6]. Cross-talk between autophagy and other types of cell death such as apoptosis has been 
extensively studied. In fact, autophagy, also known as type II cell death, can act in parallel to apoptosis or lead to cell survival by suppressing it or appearing as a pre-requisite for this type of cell death [7]. It was also observed that autophagy and apoptosis play a crucial role in ALL recurrence. Bcl2/Bax ratio, as one of the most important apoptosis regulators, is associated with relapse in ALL. In addition, ALL recurrence is related to some defects in signaling pathways such as PI3K/Akt/mTORC1 and Notch1 that are regulating autophagy [8].

Several studies have shown that natural compounds play a significant role in cancer therapy by inducing various types of cell death, including apoptosis and autophagy [9]. Epigallocatechin Gallate (EGCG) is a polyphenol derived from green tea, and the most important catechin leading to cell cycle arrest, apoptosis, proliferation arrest, and autophagy induction or inhibition in cancer cells through different pathways. It also disrupts the angiogenesis and sensitizes tumor cells, which are normally resistant to chemo- and radiotherapy [10]. In addition, several in vitro and in vivo studies have found that this compound does not damage healthy cells [11-13].

Although there is evidence showing that inhibition of autophagy doesn't affect cell viability in NALM-6 cell line [14], some observations have concluded that inhibition of autophagy leads to cell death [15,16]. There are other studies in which a decrease in cell death due to the inhibition of autophagy has been implicated in this specific cell line $[17,18]$. These different findings and the importance of the role of apoptosis, autophagy, and their cross-talk in the treatment of ALL and also lack of studies showing this interaction make it necessary to investigate the effect of EGCG on autophagy, apoptosis, and their crosstalk in NALM-6, a pre-B-ALL cell line.

\section{Methods And Materials}

\section{Cell culture and treatment}

NALM-6 cell line was purchased from Pasteur Institute (Iran, Tehran) and maintained in RPMI1640 media (Cell Biotechnology Saba Arna, Iran, Tehran) supplemented with fetal bovine serum $10 \% \mathrm{v} / \mathrm{v}$ and Penicillin/Streptomycin $100 \mathrm{IU} / \mathrm{ml}$ (Gibco Life Technologies, USA, Waltham, MA) and L-glutamine $2 \mathrm{mM}$ (Shell Max, China) at $37{ }^{\circ} \mathrm{C}$ in an environment of $5 \% \mathrm{CO}_{2}$ and humidified atmosphere of $95 \%$.

\section{MTT assay}

MTT assay was performed to indicate the impact of EGCG on NALM- 6 cell line. The cells were seeded into 96-well cell culture plates at a $1 \times 10^{4}$ density in $100 \mu \mathrm{L}$ of growth medium and incubated for at least 2 hours. EGCG (Abcam, UK, Cambridge) dissolved in DMSO (Shell Max, China) and the cells were treated with different concentrations of it $(2-110 \mu \mathrm{M})$ for 24 and 48 hours. Cell viability was evaluated, using 10 $\mu \mathrm{L}$ of $5 \mathrm{mg} / \mathrm{ml}$ sterile 3-4, 5-dimethylthiazol-2-yl-2, 5-diphenyl-tetrazolium bromide solution (Melford, UK. Ipswich) that was added to each well. Spectrometric absorbance at $545 \mathrm{~nm}$ was measured by a microplate photometer (Stat Fax 2100, USA). Three independent experiments were performed in quadruplicate. 


\section{Trypan blue exclusion assay}

Trypan blue exclusion assay was carried out to evaluate the effect of EGCG on the viability of NALM-6 cells. Briefly, the cells were seeded into a 24-well plate at a $1 \times 10^{5}$ density in $700 \mu \mathrm{L}$ of growth medium and incubated for at least 2 hours. They were then treated with different concentrations of EGCG (2-110 $\mu \mathrm{M})$ for 24 and 48 hours. The cells were then washed and resuspended in 1X PBS containing $0.4 \%$ trypan blue. They were counted, using a hemocytometer, according to standard protocol. Two independent experiments were performed in duplicate.

\section{Western blotting}

Five million NALM-6 cells were grown to 70-80\% confluency, followed by treatment with EGCG $20 \mu \mathrm{M}$ and $45 \mu \mathrm{M}$ for 36 hours. $\mathrm{NH}_{4} \mathrm{CL}$ (Merck, Germany, Darmstadt) $10 \mathrm{mM}$, dissolved in sterile deionized water, was added in the last 12 hours of incubation to inhibit autophagy. The cells were washed once with phosphate-buffered saline and then lysed, using $1 \mathrm{X}$ ice-cold lysis buffer ( $5 \mathrm{X}$ formulation: Tris- $\mathrm{HCl} 0.06 \mathrm{M}$, pH 6.8, SDS $2 \%$, Bromophenol blue $0.2 \%$, glycerol $20 \%$ ) supplemented with protease phosphatase inhibitor cocktail (Sigma-Aldrich, Germany, Darmstadt). Protein collection was performed by centrifugation at $4^{\circ} \mathrm{C}$ for 30 minutes. Bradford protein assay was used to determine protein concentration. Equal aliquots of $20 \mu \mathrm{g}$ proteins were boiled at $90^{\circ} \mathrm{C}$ for 5 minutes in $5 \mathrm{X}$ loading buffer (Tris-HCl $0.06 \mathrm{M}, \mathrm{pH} 6.8$, SDS 2\%, Bromophenol blue $0.2 \%$, glycerol 20\%), and resolved by SDS-PAGE (12\% gels). Then, samples were transferred to Polyvinylidene Fluoride (PVDF) (Roche, Switzerland, Basal) for 1 h. The blots were blocked for 1 hour with $5 \%$ skim milk in TBS-T and probed with rabbit anti-LC3 A/B antibody (Cell Signaling Technology, USA, Boston, MA) (1:1000) and mouse anti- $\beta$-Actin antibody (Santa Cruz, USA, Dallas, Texas) (1:1000) in $5 \%$ non-fat skim milk in TBS-T at $4^{\circ} \mathrm{C}$ overnight. After washing with TBS-T, the blots were treated with horseradish peroxidase-conjugated anti-rabbit IGg (Sigma-Aldrich, Germany, Darmstadt) and anti-mouse IGg (Bio-Rad, USA, Hercules, California) for 1 hour and were subsequently washed with TBS-T three times for 5 minutes each. Proteins were detected by the enhanced

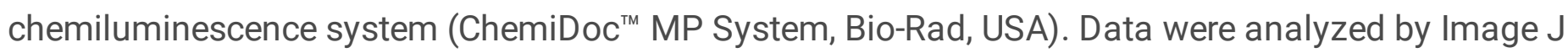
software.

\section{Flow cytometry for Apoptosis}

The cells were seeded on a 24-well plate at a $1 \times 10^{5}$ density in $700 \mu \mathrm{L}$ growth medium and incubated for at least 2 hours and treated with different concentrations of EGCG $(2-110 \mu \mathrm{M})$ for 24 and 48 hours. In addition, they were treated with EGCG $45 \mu \mathrm{M}$ for 36 hours and $\mathrm{NH}_{4} \mathrm{CL} 10 \mathrm{mM}$ was added in the last 12 hours of incubation to inhibit autophagy in combined treatments. Accessory apoptosis was determined, using PE-Annexin V/7-AAD Apoptosis Detection kit I (BD Biosciences, USA, San Jose, CA). The cells were washed with $1 \mathrm{X}$ PBS and $1 \times 10^{5}$ cells were resuspended in $100 \mu \mathrm{L}$ of $1 \mathrm{X}$ Annexin $\mathrm{V}$ binding buffer. The cells were stained with PE-Annexin $V$ and 7-AAD for 15 minutes in a dark room. They were then topped with $400 \mu \mathrm{L}$ of Annexin V binding buffer and analyzed by FACS Calibur flow cytometer (BD Biosciences) within an hour. Data were analyzed by FlowJo TreeStar LLC software. 


\section{Real-time PCR}

To determine the effect of EGCG on the expression of $P 62, \operatorname{Atg} 2 B, \angle C 3 B$, and DRAM1 genes, the cells were seeded into 6-well plates at a $1.2 \times 10^{6}$ density in $3.3 \mathrm{ml}$ of complete medium and were then treated with EGCG $45 \mu \mathrm{M}$ for 36 hours. Total RNA was extracted, using TRI Reagent (Sigma-Aldrich, Germany, Darmstadt) according to the manufacturer's instructions. The concentration of the extracted RNA was determined, using a Nanodrop instrument (Hellma, NY, China).

Complementary DNA (cDNA) was synthesized by reverse transcription, using $500 \mathrm{ng}$ of total RNA and Prime Script TM RT reagent Kit (Yektatajhiz Azma, Iran). Quantitative real-time PCR was performed, using a SYBR Premix Ex Taq (Yektatajhiz azma, Iran) in $20 \mu \mathrm{L}$ total volume. (8 $\mu \mathrm{L}$ DNase free water, $0.5 \mu \mathrm{L}$ of 10 pM forward and reverse primers, $10 \mu \mathrm{L}$ of SYBR Premix Ex Taq and $1 \mu \mathrm{L}$ of cDNA template) on a Rotor gene system (Qiagen, USA) based on the following program in Table 1. Relative quantification of gene expression was performed, using the $\beta-2$ microglobulin gene as the internal control. The qRT-PCR also included a no-template sample as a negative control. Three independent experiments were performed in triplicate and comparative relative quantification of gene expression was performed based on the Pfaffl method. The used primers, listed in Table 2, were designed by allele ID software.

Table 1

QPCR program

\begin{tabular}{|llll|}
\hline & Temperature & Time & Cycling \\
\hline Holding & $95^{\circ} \mathrm{C}$ & $1.5 \mathrm{mins}$ & 1 \\
\cline { 1 - 3 } Denaturing & $95^{\circ} \mathrm{C}$ & $5 \mathrm{sec}$ & 40 \\
\cline { 1 - 2 } Annealing & $57^{\circ} \mathrm{C}$ & $30 \mathrm{sec}$ & \\
\cline { 1 - 3 } Extension & $72^{\circ} \mathrm{C}$ & $30 \mathrm{sec}$ & \\
\hline
\end{tabular}


Table 2

Primers sequence

\begin{tabular}{|c|c|c|}
\hline \multirow{3}{*}{ P62 } & & \\
\hline & Forward & 5'- CTTTGTAGCCATCCTGTTA-3' \\
\hline & Reverse & 5'- CGACTATGTGACCTCTTTAT-3' \\
\hline \multirow[t]{2}{*}{$\angle C 3 B$} & Forward & 5'- GTGATAATAGAACGATACAAGG-3' \\
\hline & Reverse & 5'- САСТСТСАТАСАССТСТG-3' \\
\hline \multirow[t]{2}{*}{ DRAM1 } & Forward & 5'- AAGGAATGACTAAGGATGTT-3' \\
\hline & Reverse & 5'- CAGGCGATACAGACTATT-3' \\
\hline \multirow[t]{2}{*}{$\operatorname{Atg} 2 B$} & Forward & 5'- CCAGAAACTAACAGATGAACAAG-3' \\
\hline & Reverse & 5'- TCAGCAGTTTCATCACAGTACAC-3' \\
\hline \multirow[t]{2}{*}{ B2m } & Forward & 5'-TATGCCTGCCGTGTGAAC-3' \\
\hline & Reverse & 5'-CTACCTGTGGAGCAACCTG-3' \\
\hline
\end{tabular}

\section{Statistical analysis}

All analyses were performed, using the Graph Pad Prism 8.4.3 software (Graph Pad Software, Inc. La Jolla, CA) and represented as the mean \pm SEM. The data were analyzed, using Ordinary One-way ANOVA, two-way ANOVA, Kruskal-Wallis, and unpaired t-test. They were considered significant if the P-value was $<0.05$.

\section{Results}

\section{EGCG decreases cell viability of NALM-6 cell line}

The effect of different concentrations of EGCG $(2-110 \mu \mathrm{M})$ on proliferation and cell viability was evaluated by the MTT assay. We observed that EGCG caused a reduction in cell viability in a dosedependent manner. After 24 hours, cell viability was significantly reduced by $5.4 \%, 40.8 \%, 57.4 \%$, and $68.2 \%$, when exposed to EGCG 2, 20, 45, and $110 \mu \mathrm{M}$, respectively (Fig. $1 \mathrm{~A})(\mathrm{P}<0.05)$. In addition, after 48 hours of treatment with EGCG 2, 20, 45, and $110 \mu \mathrm{M}$, we detected $19.6 \%, 51.8 \%, 61.3 \%$, and $68.7 \%$ reduction in cell viability (Fig. 1B) $(P<0.05)$. To confirm the result of the MTT assay, we performed trypan blue exclusion assay. In this regard, the cells were treated with different concentrations of EGCG (2-110 $\mu \mathrm{M})$ for a duration of 24 and 48 hours. The results showed that EGCG caused a dose-dependent manner reduction in cell viability after 24 and 48 hours, significantly $(P<0.05)$ (Fig. $2 \mathrm{C}$ and $D)$.

\section{EGCG induces apoptosis in NALM-6 cell line}


To determine the effect of EGCG on apoptosis in NALM-6 cell line, flow cytometry was performed, using PE-Annexin V/7AAD Apoptosis Detection Kit I. The cells were treated with different doses of EGCG (2-110 $\mu \mathrm{M})$ for 24 and 48 hours. We observed that EGCG $20 \mu \mathrm{M}$ induced $16.7 \%$ apoptosis after 24 hours, while its rate increased to $19 \%$ after 48 hours. Besides, higher concentrations of EGCG caused a higher rate of apoptosis, so that after 24 and 48 hours we observed that EGCG $45 \mu \mathrm{M}$ led to $65.2 \%$ and $72.7 \%$ and EGCG $75 \mu \mathrm{M}$ resulted in $86 \%$ and $88.5 \%$ apoptosis, respectively. $(P<0.05)$ (Fig. 2 ).

\section{EGCG induces autophagy in NALM-6 cell line}

To investigate the effect of EGCG on autophagy, NALM- 6 cells were treated with EGCG $20 \mu \mathrm{M}$ and $45 \mu \mathrm{M}$ for 36 hours. LC3 protein level, a common marker of autophagy, was monitored, using Western Blot analysis. We showed that EGCG $45 \mu \mathrm{M}$, in comparison with $20 \mu \mathrm{M}$, caused more conversion of LC3-I to LC3-II within 36 hours (Fig. S.1). The cells were subsequently treated with $\mathrm{NH}_{4} \mathrm{Cl}$ to investigate whether the increase in LC3 level is due to an impairment of autophagic flux or activation of autophagy. There was a significant accumulation of LC3-II after 12 hours of treatment with $\mathrm{NH}_{4} \mathrm{CL} 10 \mathrm{mM}$. LC3-II expression in the cells treated with EGCG $45 \mu \mathrm{M}$ was twice as much as the untreated cells $(P<0.05)$, and when $\mathrm{NH}_{4} \mathrm{CL}$ was added, it showed more than a four-fold change, thus suggesting that activation of autophagy, rather than flux impairment, is responsible for the increased levels of LC3-II upon EGCG treatment $(P<0.01)$ (Fig. 3). Hence, EGCG $45 \mu \mathrm{M}$ proved to be the optimal concentration to be used for the rest of the experiments.

\section{EGCG affects the expression of the autophagy genes}

To further investigate whether the EGCG treatment affected the autophagy at a transcriptional level, realtime PCR was performed to evaluate the effect of EGCG $45 \mu \mathrm{M}$ treatment on autophagy-related genes such as LC3B, P62/SQSTM1, Atg2B, and DRAM1. We detected that treatment of the cells with EGCG 45 $\mu \mathrm{M}$ led to a significant reduction of the expression of $\angle C 3 B, P 62, \operatorname{Atg} 2 B$, and genes, $33.3 \%(\mathrm{P}<0.01), 46.5 \%$ (0.0001), and 45.5\% ( $<<0.0001)$, respectively. We also assessed the impact of EGCG $45 \mu \mathrm{M}$ on DRAM1 expression and observed a 1.3-fold increase in its expression level $(P<0.05)$ (Fig. 4).

\section{Inhibition of Autophagy does not interfere with apoptosis in NALM-6 cell line}

To determine the effect of autophagy on apoptosis in NALM-6 cells, FACS analysis was performed, using FITC-Annexin V/PI Apoptosis Detection Kit I. The cells were treated with EGCG $45 \mu \mathrm{M}$ for 36 hours in the presence and absence of $\mathrm{NH}_{4} \mathrm{CL} 10 \mathrm{mM}$ in the last 12 hours of incubation. As shown in Figure 5 , autophagy inhibition by $\mathrm{NH}_{4} \mathrm{CL}$ did not affect the rate of apoptosis in untreated and treated cells.

\section{Discussion}


Although new strategies have significantly improved chemotherapy outcomes in pediatric ALL patients, the prognosis is still poor amongst adults and infants [19]. Identifying a natural compound with minimum toxicity and high efficacy will help develop a novel therapy, which might improve the response to currently available therapies. There are numerous studies regarding the effect of EGCG on cell viability or apoptosis in leukemic cell lines while its effect on autophagy or cross-talk between autophagy and apoptosis in leukemia has not been previously explored. Here, we focused on B lymphoblastic leukemia and studied the effect of EGCG on autophagy, apoptosis, and their interaction in NALM-6 cell line.

The anti-proliferative and cytotoxic effect of EGCG has been investigated in different cancer cell lines, animal models, as well as clinical trials [20]. It has been stated that this compound inhibits proliferation and induces DNA fragmentation in different human leukemic cell lines in a dose-dependent manner [21]. In the present study, we showed that EGCG significantly reduces NALM-6 cell viability $(P<0.0001)$ (Fig. 1).

It is now well established that apoptosis induction is a crucial approach in cancer therapy. Cornwall Cull, et al. have indicated that EGCG results in apoptosis in B-CLL and T-CLL cells in a dose-dependent manner, while it does not affect normal B and T cells [22]. Furthermore, it has been observed that EGCG induces apoptosis in Jurkat cell line through the expression of Fas and increasing Caspase 3 levels [23]. It has been also shown that EGCG prompts apoptosis in leukemic cells such as KG-1, TH-P1, and PML/RARa leukemic mice $[24,25]$. The results of our study also showed that EGCG treatment results in apoptosis in NALM-6 cell line in a dose-dependent manner, which is in accordance with the study of Fatih M. Uckun, et al. showing that EGCG $10 \mu \mathrm{g} / \mathrm{ml}$ and $50 \mu \mathrm{g} / \mathrm{ml} \mu \mathrm{M}$ caused about 22.5 and $67.8 \%$ apoptosis in a $24 \mathrm{~h}$ duration in NALM-6 cell line, respectively [26]. We observed that treatment with EGCG $45 \mu \mathrm{M}$ can significantly increase apoptosis after 24 and 48 hours $(P<0.05)$ (Fig. 2), the concentration which also caused a significant rate of proliferation arrest (Fig. 1).

Since autophagy and apoptosis induction pathways are related [27] and autophagy plays a dual role in the pathophysiology of cancer [6], several studies have been conducted to investigate the effect of EGCG treatment on both apoptosis and autophagy mechanisms and their cross-talk. It has been reported that EGCG induces apoptosis and autophagy in five different mesothelium cell lines while treating these cells with EGCG in the presence of chloroquine, an autophagy inhibitor, leads to cell death [28]. Besides, it has been shown that EGCG antagonizes proteasome inhibitors bortezomib toxicity by autophagy induction and protecting PC3 cells from death [29]. However, there is evidence that has demonstrated that activation of autophagic flux by EGCG decreases TRAIL-induced apoptosis in HCT-116, a colon-cancer cell line, by downregulation of death receptors [30]. Interestingly, Jiao Meng, et al. have shown that cotreatment of A549, a non-small cell lung cancer cell line, with EGCG and gefitinib can sensitize them to this drug by autophagy inhibition; hence, this resistance might be due to the induction of cytoprotective autophagy in this cell line [31]. In the present study, we examined the effect of EGCG on autophagy and apoptosis in the presence and absence of $\mathrm{NH}_{4} \mathrm{CL}$, an autophagy inhibitor, to investigate how autophagy affects NALM-6 cell survival. Western blot analysis for LC3-II, one of the most important markers of autophagy, showed that EGCG $45 \mu \mathrm{M}$ significantly induces autophagy in NALM-6 cell line $(P<0.05)$. However, autophagy inhibition by $\mathrm{NH}_{4} \mathrm{CL}$ didn't affect apoptosis in the presence or absence of EGCG. In 
fact, our data are in line with Wong, $\mathrm{J}$ et al. that have shown that inhibition of autophagy doesn't affect apoptosis in NALM-6 cell line, contrary to others who either revealed that inhibition of autophagy increases cell death $[15,16]$ or showing that inhibition of autophagy can be cytoprotective for this cell line $[18,14]$.

Recently, researches have shown that an entire network of transcription factors like FOXO, STAT1, STAT3, NF-KB, and TP53 are involved in the modulation of autophagy. Indeed, several transcription factors including TP53, STAT3, and NF-kB play a dual role in autophagy regulation, through both transcriptional (nuclear interaction) and transcriptional-independent (cytoplasmic interaction) mechanisms, acting as both activators and repressors. In addition, autophagy is regulated by post-transcriptional effectors, including microRNAs, siRNAs, IncRNAs, or post-translational mechanisms such as phosphorylation, ubiquitination, acetylation, as well as histones acetylation [32,33]. Some pieces of evidence have shown that EGCG can affect the expression of downstream autophagy genes by inhibiting Sp1, NF-KB, AP-1, STAT1, STAT3, and FOXO1 or activation of Nrf2 and TP53 transcription factors [34]. It has been also indicated that EGCG participates in gene expression regulation through interfering with the methylation or expression level of miRNAs [35].

In addition, studies have stated that the molecular mechanism of autophagy involves several conserved genes such as MAP1LC3, SQSTM1/P62, Atg2B, and DRAM1 [36]. It has been shown that MAP1LC3 gene expression, with an important role in autophagy induction, may change differently and it is regulated by numerous transcription factors such as ATF4, C/EBP $\beta$, FOX01, FOXO3, GATA1, and TFEB [37]. SQSTM1/P62 gene also codes an important protein involved in autophagy, transcribed by NF-هB, $\beta-$ catenin, and TFEB [38]. In addition, Atg2B, an essential protein in the autophagy process localizes on the autophagy membrane or the surface of lipid droplets [39]. DRAM1 also known as DNA damage-regulated autophagy modulator 1 , transcribed by P53, modulates autophagy and apoptosis $[40,41]$. It plays an essential role in apoptosis regulation involving BAX and lysosomes [42] and genotoxic stress-induced autophagy [43].

Tumenjin Enkhbat, et al. have shown that treatment of HCT-116 cell line, with EGCG $12.5 \mu \mathrm{M}$ for $48 \mathrm{~h}$ in combination with 2 Gy radiation up-regulated $\angle C 3$ mRNA. While treatment with EGCG alone caused about a 4-fold change, radiation itself led to an 11-fold change and when they were combined, a change over 15-fold was observed [44]. In contrast, $L i$, et al. showed that EGCG $20 \mu \mathrm{M}$ did not alter LC3 mRNA expression in primary hepatocytes, whereas in the pretreated animal models with concanavalin $A$, a plant lectin that used to induce acute hepatitis, EGCG resulted in a significant decrease in $L C 3$ mRNA level in liver tissue [45]. We also observed that treatment of NALM-6 with EGCG $45 \mu \mathrm{M}$ for 36 hours led to a significant decrease in the $L C 3$ mRNA level compared to untreated cells $(P<0.01)$, which is in line with the Sainan Li study. Decreasing the LC3 mRNA level may be related to the FOXO1 transcription factor which has been previously shown to be inhibited by EGCG [46].

Regarding P62 expression, Zhong, L. et al. have investigated the effect of EGCG $25 \mu \mathrm{M}$ and $50 \mu \mathrm{M}$ on P62 protein and mRNA level in HepG2, a hepatocarcinoma cell line. They observed that EGCG led to the 
downregulation of the P62 protein level but it did not affect the P62 mRNA level significantly [47]. Li, et al. also have found that EGCG $20 \mu \mathrm{M}$ did not affect P62 mRNA expression in primary hepatocytes [45]. Nonetheless, it has been reported that the treatment of DIV8 primary rat cortical neurons with EGCG 50 $\mu \mathrm{M}$ for 24 hours caused a significant increase in mRNA levels of $P 62$ compared to DMSO control $(P<0.05)$ [48]. In the present study, we revealed that EGCG $45 \mu \mathrm{M}$ caused a significant decrease in the P62/SQSTM1 mRNA level $(P<0.0005)$. P62 is one of the $\mathrm{Nf}-\mathbb{B} \mathrm{B}$ target genes that can itself be inhibited by EGCG, thus decreasing its mRNA levels [34].

In contrast to $\angle C 3 B$ and SQSTM1/P62 genes, there is no evidence concerning the effect of EGCG on $A t g 2 B$ and $D R A M 1$ genes. We observed that $A T G 2 B$ mRNA expression level reduces significantly in response to the treatment of NALM- 6 with EGCG $45 \mu \mathrm{M}$ after $36 \mathrm{~h}(\mathrm{P}<0.0001)$. However, it was reported that $A \operatorname{tg} 2 B$ gene expression remained constant in MEFs (mouse embryonic fibroblast cells), in response to starvation after $2,4,6$, and 8 hours, while, an early upregulation was followed by a later reduction in other autophagy genes and protein markers [49]. Moreover, it has been observed that starvation induces DRAM-1 mediated autophagy in 7702, HepG2, Hep3B, and Huh7 cells. These cell lines were starved for 48 $\mathrm{h}$ and DRAM1 mRNA and protein levels had increased significantly [50]. We also observed that treatment of NALM- 6 cell line with EGCG $45 \mu \mathrm{M}$ results in a slight but significant increase in DRAM1 gene expression $(\mathrm{P}<0.05)$. Therefore, our data suggest that the reduction of the mRNA levels of autophagy genes and increasing the mRNA levels of DRAM-1 might be related to apoptosis induction with EGCG 45 $\mu \mathrm{M}$. Nonetheless, observing the decreased expression of autophagy genes, while observing the induction of autophagy upon EGCG treatment in NALM- 6 cells, might be due to post-transcriptional or posttranslational alterations. Therefore, more investigations are required to find the exact mechanism by which EGCG affects the expression of these genes.

In conclusion, we observed that EGCG decreases the cell viability and induces apoptosis in NALM-6 cell line in a time- and dose-dependent manner. It also results in autophagy induction dose-dependently, and also an alteration in $\angle C 3 B, P 62, A \operatorname{tg} 2 B$, and $D R A M 1$ gene expression. Furthermore, inhibition of autophagy does not interfere with the apoptotic cell death induced by EGCG. Considering the importance of autophagy as a secondary cell death mechanism, it would be of great importance to further study the possible involvement of EGCG in inducing autophagic cell death in cells in which the apoptotic pathway is impaired. This compound can also be used in combination with chemotherapeutic drugs to study leukemic cell lines or animal models. Investigating the effect of this combination on autophagy and cell death or proliferation could be beneficial in cancer therapy.

\section{Abbreviations}

ALL

Acute lymphoblastic leukemia

AP-1

Activator protein 1

ATG

Page 10/21 
Autophagy-related protein

b2M

$\beta 2$ macroglobulin

\section{BAX}

BCL2 associated $X$

apoptosis regulator

\section{DRAM1}

Damage-regulated autophagy modulator 1

EGCG

Epigallocatechin Gallate

Gy

Gray

HCC

Hepatocellular carcinoma

\section{MAPLC3}

Microtubule-associated protein 1 light chain 3

\section{NF-kB}

Nuclear factor kappa-light-chain-enhancer of activated B cells

Nrf2

Nuclear factor erythroid 2-related factor 2

\section{F0X01}

Forkhead Box 01

Sp1

Specificity protein 1

\section{SQSTM1}

Sequestosome 1

STAT

Signal transducer and activator of transcription

TP53

Tumor protein p53

TRAIL

TNF-related apoptosis-inducing ligand

\section{Declarations}

\section{Acknowledgments}

This study was extracted from a Master's thesis by Faezeh Gharehchahi, an MSc student of hematology and blood bank at Shiraz University of Medical Sciences, Shiraz, Iran. We would like to thank Shiraz University of Medical Sciences for supporting this study. We also extend our gratitude to the staff of the 
Diagnostic Laboratory Sciences and Technology Research Center of the School of Paramedical Sciences, Shiraz University of Medical Sciences, Shiraz, Iran.

\section{Funding}

This article was extracted from a Master's thesis in hematology and blood banking by Faezeh Gharehchahi, supported by Shiraz University of Medical Sciences (grant No.: 16536).

\section{Competing Interests}

We declare no conflicts of interest.

\section{Authors' contributions}

Gholamhosein Tamaddon: Project administration, Supervision, Funding acquisition, Resources

Somayeh Pourpirali: Supervision, Conceptualization, Methodology, Validation, Writing- Reviewing and Editing

Faezeh Gharehchahi: Conceptualization, Methodology, Investigation, Visualization, Data curation, WritingOriginal draft preparation

Farahnaz Zare: Visualization, Data curation

Gholamreza Rafie Dehbidi: Visualization, Data curation

Zahra Yousefi: Software, Validation, Formal analysis

\section{Ethics approval}

This study was approved by the Ethics Committee of Shiraz University of Medical Sciences (IR.SUMS.REC.1397.289).

\section{Consent to participate}

This was an in vitro study and we did not present any patient information; therefore, there was no need to obtain informed consent.

\section{Consent to publish}




\section{References}

1. Bassan R, Brüggemann M, Radcliffe HS, Hartfield E, Kreuzbauer G, Wetten S (2019) A systematic literature review and meta-analysis of minimal residual disease as a prognostic indicator in adult Bcell acute lymphoblastic leukemia. Haematologica 104 (10):2028-2039.

doi:10.3324/haematol.2018.201053

2. Terwilliger T, Abdul-Hay M (2017) Acute lymphoblastic leukemia: a comprehensive review and 2017 update. Blood cancer journal 7 (6):e577. doi:10.1038/bcj.2017.53

3. Huang FL, Liao EC, Li CL, Yen CY, Yu SJ (2020) Pathogenesis of pediatric B-cell acute lymphoblastic leukemia: Molecular pathways and disease treatments. Oncology letters 20 (1):448-454. doi:10.3892/ol.2020.11583

4. Man LM, Morris AL, Keng M (2017) New Therapeutic Strategies in Acute Lymphocytic Leukemia. Current hematologic malignancy reports 12 (3):197-206. doi:10.1007/s11899-017-0380-3

5. Khandia R, Dadar M, Munjal A, Dhama K, Karthik K, Tiwari R, Yatoo MI, Iqbal HMN, Singh KP, Joshi SK, Chaicumpa W (2019) A Comprehensive Review of Autophagy and Its Various Roles in Infectious, Non-Infectious, and Lifestyle Diseases: Current Knowledge and Prospects for Disease Prevention, Novel Drug Design, and Therapy. Cells 8 (7). doi:10.3390/cells8070674

6. Lorente J, Velandia C, Leal JA, Garcia-Mayea Y, Lyakhovich A, Kondoh H, ME LL (2018) The interplay between autophagy and tumorigenesis: exploiting autophagy as a means of anticancer therapy. Biol Rev Camb Philos Soc 93 (1):152-165. doi:10.1111/brv.12337

7. Sever ON, Demir OG (2017) Autophagy: cell death or survive mechanism. Journal of Oncological Sciences 3 (2):37-44. doi:10.1016/j.jons.2017.07.001

8. Huang FL, Yu SJ, Li CL (2021) Role of Autophagy and Apoptosis in Acute Lymphoblastic Leukemia. Cancer control : journal of the Moffitt Cancer Center 28:10732748211019138. doi: $10.1177 / 10732748211019138$

9. Yuan R, Hou Y, Sun W, Yu J, Liu X, Niu Y, Lu JJ, Chen X (2017) Natural products to prevent drug resistance in cancer chemotherapy: a review. Ann N Y Acad Sci 1401 (1):19-27. doi: $10.1111 /$ nyas. 13387

10. Lecumberri E, Dupertuis YM, Miralbell R, Pichard C (2013) Green tea polyphenol epigallocatechin-3gallate (EGCG) as adjuvant in cancer therapy. Clin Nutr 32 (6):894-903. doi:10.1016/j.clnu.2013.03.008

11. Babich H, Krupka ME, Nissim HA, al ae (2005) Differential in vitro cytotoxicity of (-)-epicatechin gallate (ECG) to cancer and normal cells from the human oral cavity. Toxicol In Vitro 19 (2):231-242. doi:10.1016/j.tiv.2004.09.001

12. Isbrucker RA, Edwards JA, Wolz E, Davidovich A, Bausch J (2006) Safety studies on epigallocatechin gallate (EGCG) preparations. Part 2: dermal, acute and short-term toxicity studies. Food Chem 
Toxicol 44 (5):636-650. doi:10.1016/j.fct.2005.11.003

13. Isbrucker RA, Edwards JA, Wolz E, Davidovich A, Bausch J (2006) Safety studies on epigallocatechin gallate (EGCG) preparations. Part 3: teratogenicity and reproductive toxicity studies in rats. Food Chem Toxicol 44 (5):651-661. doi:10.1016/j.fct.2005.11.002

14. Wong J, Welschinger R, Hewson J, Bradstock KF, Bendall LJ (2014) Efficacy of dual PI-3K and mTOR inhibitors in vitro and in vivo in acute lymphoblastic leukemia. Oncotarget 5 (21):10460-10472. doi:10.18632/oncotarget.2260

15. Wang Z, Zhu S, Zhang G, Liu S (2015) Inhibition of autophagy enhances the anticancer activity of bortezomib in B-cell acute lymphoblastic leukemia cells. Am J Cancer Res 5 (2):639-650

16. Skah S, Richartz N, Duthil E, Gilljam KM, Bindesbøll C, Naderi EH, Eriksen AB, Ruud E, Dirdal MM, Simonsen A, Blomhoff HK (2018) cAMP-mediated autophagy inhibits DNA damage-induced death of leukemia cells independent of p53. Oncotarget 9 (54):30434-30449. doi:10.18632/oncotarget.25758

17. Sharma A, Singh K, Mazumder S, Hill BT, Kalaycio M, Almasan A (2013) BECN1 and BIM interactions with MCL-1 determine fludarabine resistance in leukemic B cells. Cell Death Dis 4 (5):e628. doi:10.1038/cddis.2013.155

18. Simioni C, Cani A, Martelli AM, Zauli G, Tabellini G, McCubrey J, Capitani S, Neri LM (2014) Activity of the novel mTOR inhibitor Torin-2 in B-precursor acute lymphoblastic leukemia and its therapeutic potential to prevent Akt reactivation. Oncotarget 5 (20):10034-10047. doi:10.18632/oncotarget.2490

19. Lee JW, Cho B (2017) Prognostic factors and treatment of pediatric acute lymphoblastic leukemia. Korean journal of pediatrics 60 (5):129-137. doi:10.3345/kjp.2017.60.5.129

20. Cheng Z, Zhang Z, Han Y, al ae (2020) A review on anti-cancer effect of green tea catechins. Journal of Functional Foods 74:104172. doi:https://doi.org/10.1016/j.jff.2020.104172

21. Cotoraci C, Ciceu A, Sasu A, Miutescu E, Hermenean A (2021) The Anti-Leukemic Activity of Natural Compounds. Molecules (Basel, Switzerland) 26 (9). doi:10.3390/molecules26092709

22. Cornwall S, Cull G, Joske D, Ghassemifar R (2016) Green tea polyphenol "epigallocatechin-3-gallate", differentially induces apoptosis in CLL B-and T-Cells but not in healthy B-and T-Cells in a dose dependant manner. Leuk Res 51:56-61. doi:10.1016/j.leukres.2016.10.011

23. Ghasemi-Pirbaluti M, Pourgheysari B, Shirzad H, Sourani Z, Beshkar P (2018) The Inhibitory Effect of Epigallocatechin Gallate on the Viability of T Lymphoblastic Leukemia Cells is Associated with Increase of Caspase-3 Level and Fas Expression. Indian J Hematol Blood Transfus 34 (2):253-260. doi:10.1007/s12288-017-0854-4

24. Wu M, Jiang M, Xue M, Li Q, Cheng B, Huang M, Xu L, Zhang Y (2020) [Epigallocatechin gallate induces CHD5 gene demethylation to promote acute myeloid leukemia cell apoptosis in vitro by regulating p19(Arf)-p53-p21(Cip1) signaling pathway]. Nan fang yi ke da xue xue bao = Journal of Southern Medical University 40 (9):1230-1238. doi:10.12122/j.issn.1673-4254.2020.09.02

25. Della Via FI, Shiraishi RN, Santos I, Ferro KP, Salazar-Terreros MJ, Franchi Junior GC, Rego EM, Saad STO, Torello CO (2021) (-)-Epigallocatechin-3-gallate induces apoptosis and differentiation in 
leukaemia by targeting reactive oxygen species and PIN1. Scientific reports 11 (1):9103. doi:10.1038/s41598-021-88478-z

26. Uckun FM, Qazi S, Ozer Z, Garner AL, Pitt J, Ma H, Janda KD (2011) Inducing apoptosis in chemotherapy-resistant B-lineage acute lymphoblastic leukaemia cells by targeting HSPA5, a master regulator of the anti-apoptotic unfolded protein response signalling network. Br J Haematol 153 (6):741-752. doi:10.1111/j.1365-2141.2011.08671.x

27. D'Arcy MS (2019) Cell death: a review of the major forms of apoptosis, necrosis and autophagy. Cell biology international 43 (6):582-592. doi:10.1002/cbin.11137

28. Satoh M, Takemura Y, Hamada H, Sekido Y, Kubota S (2013) EGCG induces human mesothelioma cell death by inducing reactive oxygen species and autophagy. Cancer Cell Int 13 (1):19. doi:10.1186/1475-2867-13-19

29. Modernelli A, Naponelli V, Giovanna Troglio M, Bonacini M, Ramazzina I, Bettuzzi S, Rizzi F (2015) EGCG antagonizes Bortezomib cytotoxicity in prostate cancer cells by an autophagic mechanism. Scientific reports 5:15270. doi:10.1038/srep15270

30. Kim SW, Moon JH, Park SY (2016) Activation of autophagic flux by epigallocatechin gallate mitigates TRAIL-induced tumor cell apoptosis via down-regulation of death receptors. Oncotarget 7 (40):65660-65668. doi:10.18632/oncotarget.11597

31. Meng J, Chang C, Chen Y, Bi F, Ji C, Liu W (2019) EGCG overcomes gefitinib resistance by inhibiting autophagy and augmenting cell death through targeting ERK phosphorylation in NSCLC. OncoTargets and therapy 12:6033-6043. doi:10.2147/ott.s209441

32. Feng Y, Yao Z, Klionsky DJ (2015) How to control self-digestion: transcriptional, post-transcriptional, and post-translational regulation of autophagy. Trends Cell Biol 25 (6):354-363. doi:10.1016/j.tcb.2015.02.002

33. Sun T (2018) Long noncoding RNAs act as regulators of autophagy in cancer. Pharmacol Res 129:151-155. doi:10.1016/j.phrs.2017.11.009

34. Kim HS, Quon MJ, Kim JA (2014) New insights into the mechanisms of polyphenols beyond antioxidant properties; lessons from the green tea polyphenol, epigallocatechin 3-gallate. Redox Biol 2:187-195. doi:10.1016/j.redox.2013.12.022

35. Aggarwal V, Tuli HS, Tania M, Srivastava S, Ritzer EE, Pandey A, Aggarwal D, Barwal TS, Jain A, Kaur G, Sak K, Varol M, Bishayee A (2020) Molecular mechanisms of action of epigallocatechin gallate in cancer: Recent trends and advancement. Seminars in cancer biology.

doi:10.1016/j.semcancer.2020.05.011

36. Ambrosio S, Majello B (2020) Autophagy Roles in Genome Maintenance. Cancers 12 (7). doi:10.3390/cancers 12071793

37. Füllgrabe J, Ghislat G, Cho DH, Rubinsztein DC (2016) Transcriptional regulation of mammalian autophagy at a glance. Journal of cell science 129 (16):3059-3066. doi:10.1242/jcs.188920

38. Sakamaki JI, Long JS, New M, Van Acker T, Tooze SA, Ryan KM (2018) Emerging roles of transcriptional programs in autophagy regulation. Transcription 9 (2):131-136. 
doi:10.1080/21541264.2017.1372045

39. Velikkakath AK, Nishimura T, Oita E, Ishihara N, Mizushima N (2012) Mammalian Atg2 proteins are essential for autophagosome formation and important for regulation of size and distribution of lipid droplets. Mol Biol Cell 23 (5):896-909. doi:10.1091/mbc.E11-09-0785

40. Crighton D, Wilkinson S, O'Prey J, Syed N, Smith P, Harrison PR, al ae (2006) DRAM, a p53-induced modulator of autophagy, is critical for apoptosis. Cell 126 (1):121-134.

doi:10.1016/j.cell.2006.05.034

41. Mah LY, O'Prey J, Baudot AD, Hoekstra A, Ryan KM (2012) DRAM-1 encodes multiple isoforms that regulate autophagy. Autophagy 8 (1):18-28. doi:10.4161/auto.8.1.18077

42. Guan JJ, Zhang XD, Sun W, Qi L, Wu JC, Qin ZH (2015) DRAM1 regulates apoptosis through increasing protein levels and lysosomal localization of BAX. Cell Death Dis 6 (1):e1624. doi:10.1038/cddis.2014.546

43. Nagata M, Arakawa S, Yamaguchi H, Torii S, Endo H, Tsujioka M, Honda S, Nishida Y, Konishi A, Shimizu S (2018) Dram1 regulates DNA damage-induced alternative autophagy. Cell Stress 2 (3):5565. doi:10.15698/cst2018.03.127

44. Enkhbat T, Nishi M, Yoshikawa K, Jun H, Tokunaga T, Takasu C, al ae (2018) Epigallocatechin-3gallate Enhances Radiation Sensitivity in Colorectal Cancer Cells Through Nrf2 Activation and Autophagy. Anticancer Res 38 (11):6247-6252. doi:10.21873/anticanres.12980

45. Li S, Xia Y, Chen K, Li J, Liu T, Wang F, al ae (2016) Epigallocatechin-3-gallate attenuates apoptosis and autophagy in concanavalin A-induced hepatitis by inhibiting BNIP3. Drug Des Devel Ther 10:631647. doi:10.2147/dddt.s99420

46. Li X, Chen Y, Shen JZ, Pan Q, Yang W, Yan H, Liu H, Ai W, Liao W, Guo S (2019) Epigallocatechin Gallate Inhibits Hepatic Glucose Production in Primary Hepatocytes via Downregulating PKA Signaling Pathways and Transcriptional Factor Fox01. Journal of agricultural and food chemistry 67 (13):3651-3661. doi:10.1021/acs.jafc.9b00395

47. Zhong L, Hu J, Shu W, Gao B, Xiong S (2015) Epigallocatechin-3-gallate opposes HBV-induced incomplete autophagy by enhancing lysosomal acidification, which is unfavorable for HBV replication. Cell Death Dis 6 (5):e1770. doi:10.1038/cddis.2015.136

48. Chesser AS, Ganeshan V, Yang J, Johnson GV (2016) Epigallocatechin-3-gallate enhances clearance of phosphorylated tau in primary neurons. Nutr Neurosci 19 (1):21-31. doi:10.1179/1476830515y.0000000038

49. B'Chir W, Maurin AC, Carraro V, Averous J, Jousse C, Muranishi Y, al ae (2013) The elF2a/ATF4 pathway is essential for stress-induced autophagy gene expression. Nucleic Acids Res 41 (16):76837699. doi:10.1093/nar/gkt563

50. Liu K, Shi Y, Guo XH, Ouyang YB, Wang SS, Liu DJ, al ae (2014) Phosphorylated AKT inhibits the apoptosis induced by DRAM-mediated mitophagy in hepatocellular carcinoma by preventing the translocation of DRAM to mitochondria. Cell Death Dis 5 (2):e1078. doi:10.1038/cddis.2014.51 

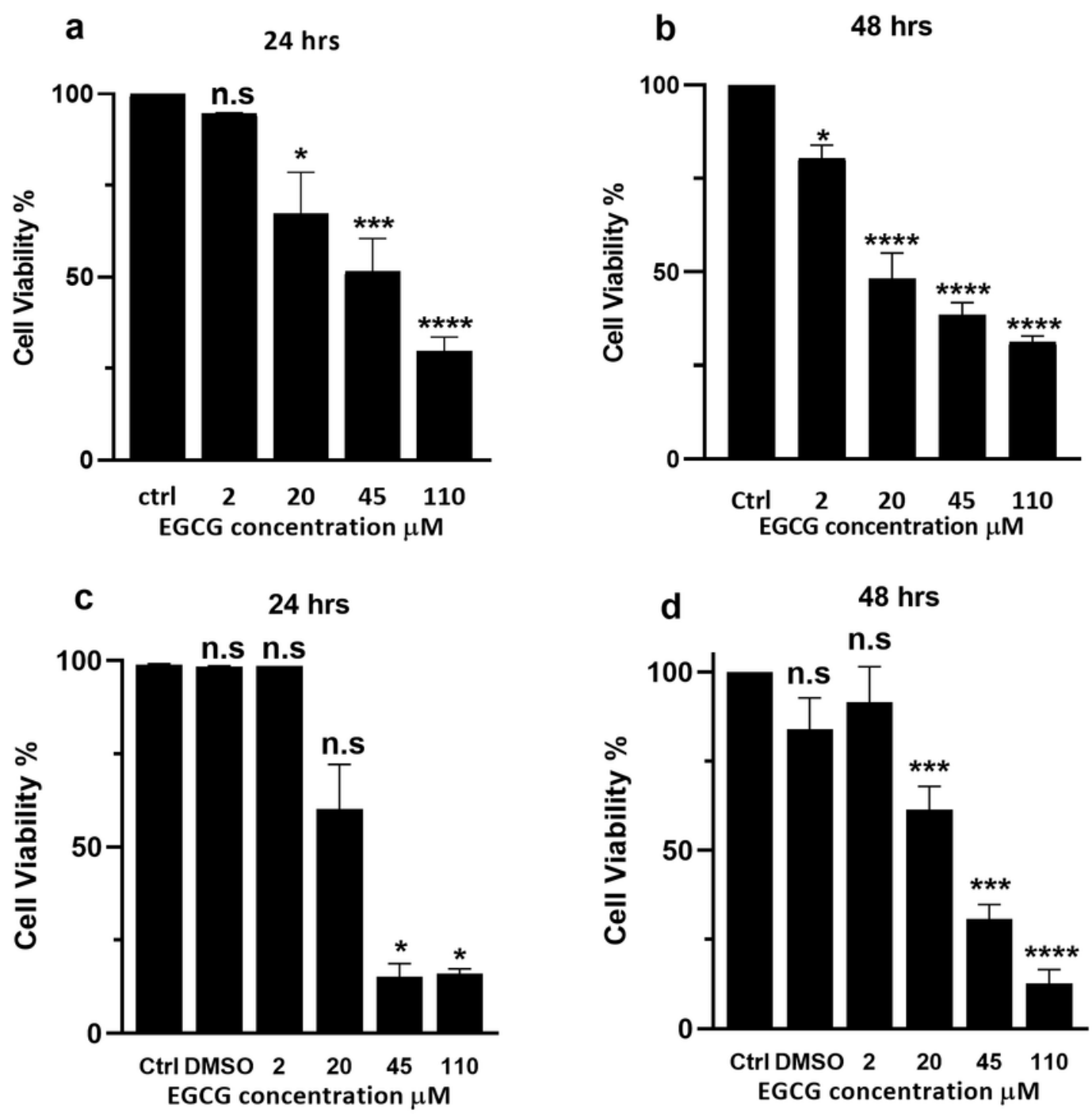

Figure 1

The effect of EGCG on proliferation and cell viability in NALM-6 cell line. EGCG reduced the viability of NALM- 6 cells in a dose-dependent manner. The cells were incubated with different doses of EGCG (2-110 $\mu \mathrm{M})$ for 24 and 48 hours. Data represented in graphs $A$ and $B$ as mean \pm SEM of three independent MTT assay experiments performed in quadruplicate. In addition, data represented in graphs C and D as mean \pm 
SEM of two independent trypan blue exclusion assay experiments performed in duplicate. MTT, 3- (4, 5dimethylthiazol-2-yl) -2, 5 -diphenyl -tetrazolium bromide. Ordinary one-way ANOVA was used to analyze. ( ${ }^{*}<0.05, * \star * P<0.005,{ }^{* \star * * P} \mathrm{P}<0.0001$ n. s: Non-significant).
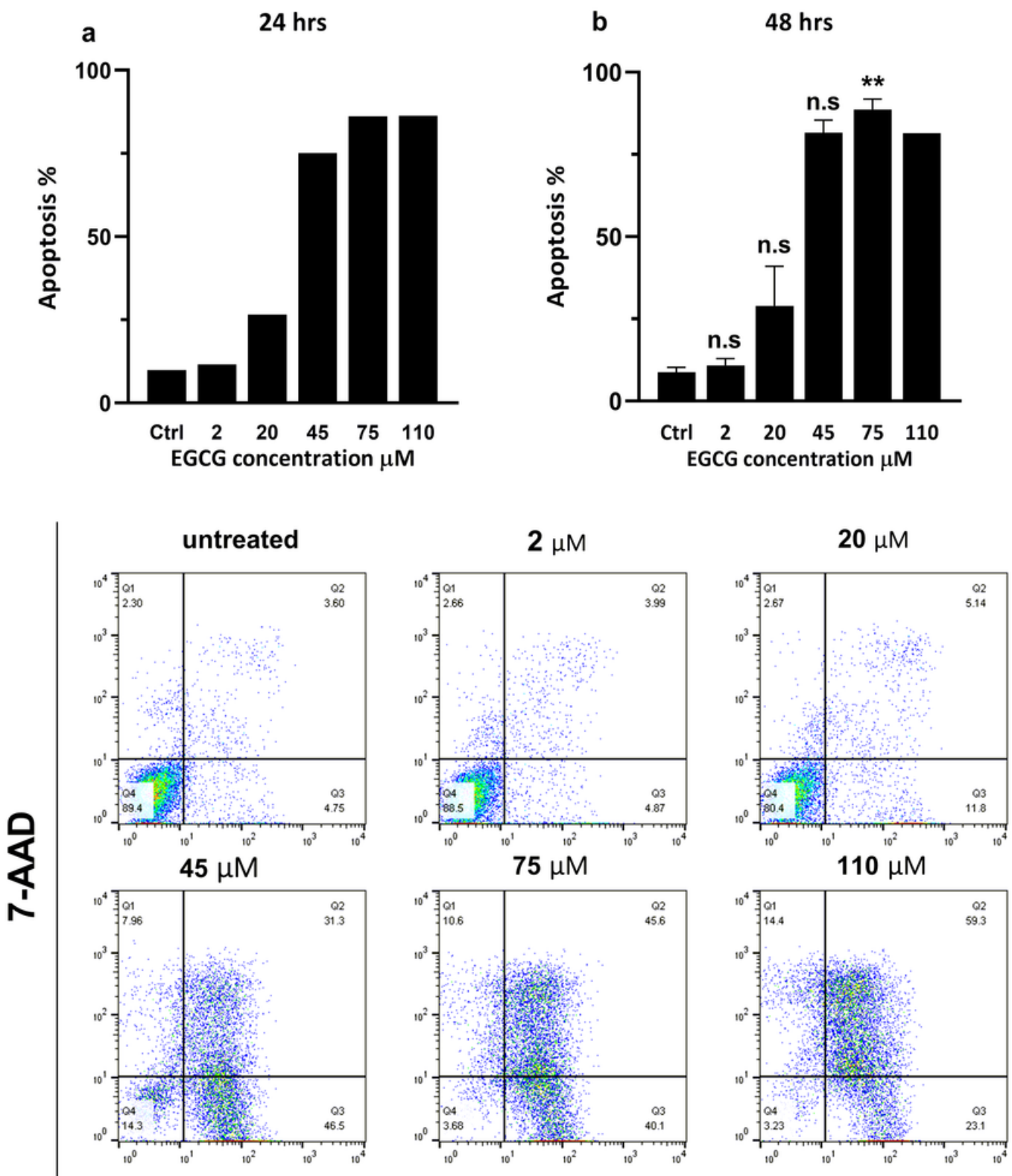

\section{PE-Annexin V}

Figure 2

The effect of EGCG on apoptosis in NALM-6 cells. Cells were treated with different concentrations of EGCG $(2-110 \mu \mathrm{M})$ for 24 hours and 48 hours. Data represented as mean \pm SEM of two independent experiments in (A) 24 and (B) 48 hours in duplicate. Depicted, using a BD FACS caliber flow cytometer. 
Annexin V-PE- 7-AAD- located in the left lower quadrant of the corresponding two-color FACS histogram assumed as live cells, and substantially Annexin V-PE+ apoptotic cells located in the right quadrants assumed as apoptotic cells. Kruskal-Wallis test was performed to analyze the data. $\left({ }^{\star} P<0.05, n\right.$. s: Nonsignificant)

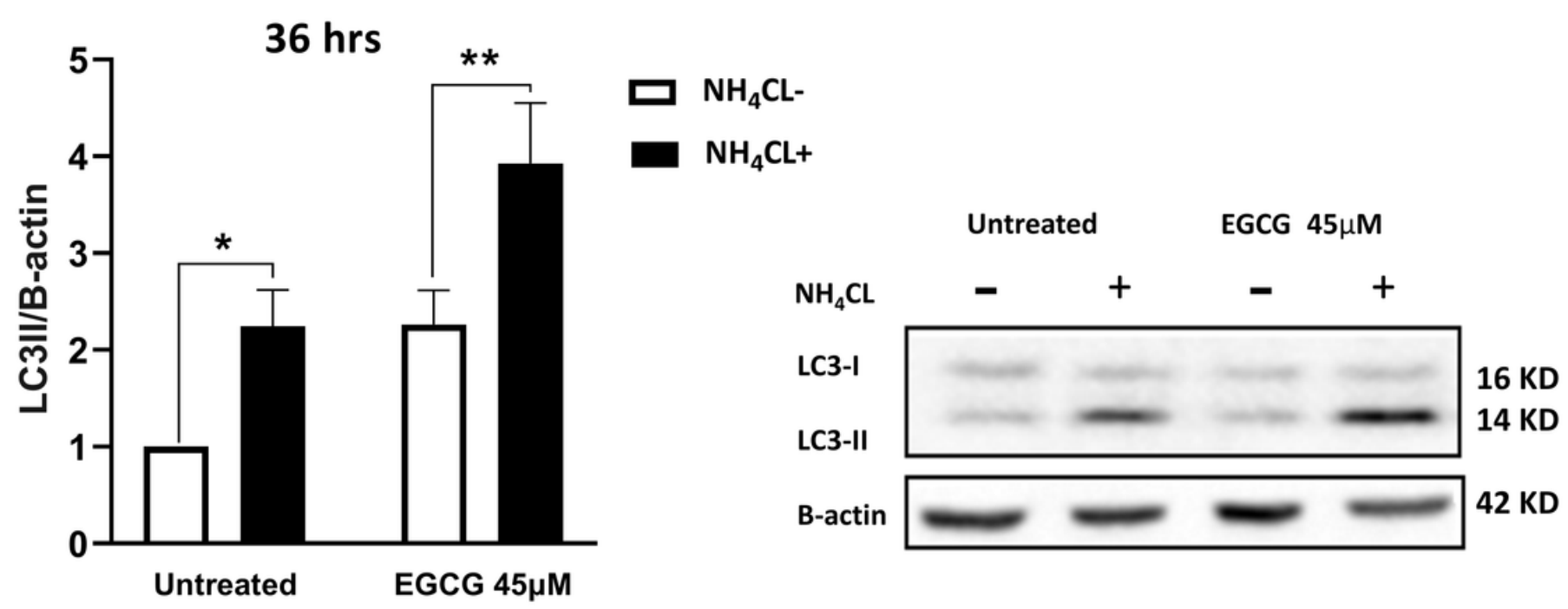

Figure 3

The effect of EGCG on autophagy in NALM- 6 cells Cells were incubated with EGCG $45 \mu$ M for 36 hours in the presence or absence of $\mathrm{NH} 4 \mathrm{CL}$ during the last 12 hours. The LC3II level was increased by 1.85 and 4.5 folds, in the absence and presence of autophagy inhibitor respectively. Data represented as mean \pm SEM of three independent experiments in triplicate. Two-way ANOVA was used to analyze the data. $\left({ }^{*} P<0.05\right.$, n. s: Non-significant) 


\section{$36 \mathrm{hrs}$}

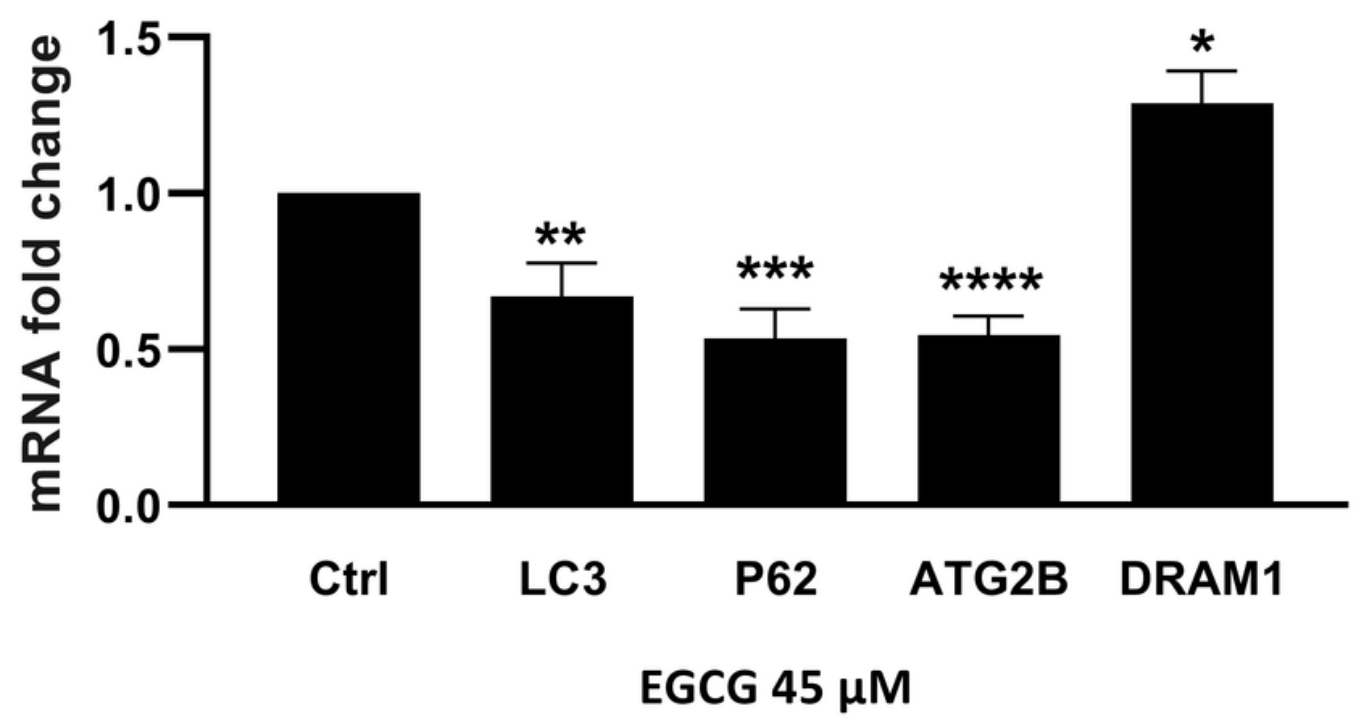

Figure 4

The effect of EGCG $45 \mu \mathrm{M}$ on P62, LC3B, Atg2B, and DRAM1 mRNA expression P62, LC3B, and Atg2B mRNA levels were reduced upon EGCG $45 \mu \mathrm{M}$ treatment while DRAM1 mRNA levels were slightly but significantly increased. Data represented as mean \pm SEM of three independent experiments in triplicate. Unpaired t-test was performed to analyze the data. $\left({ }^{*} P<0.05,{ }^{*} P<0.01,{ }^{*} * * P<0.0005\right.$, n. s: Non-significant) 
a

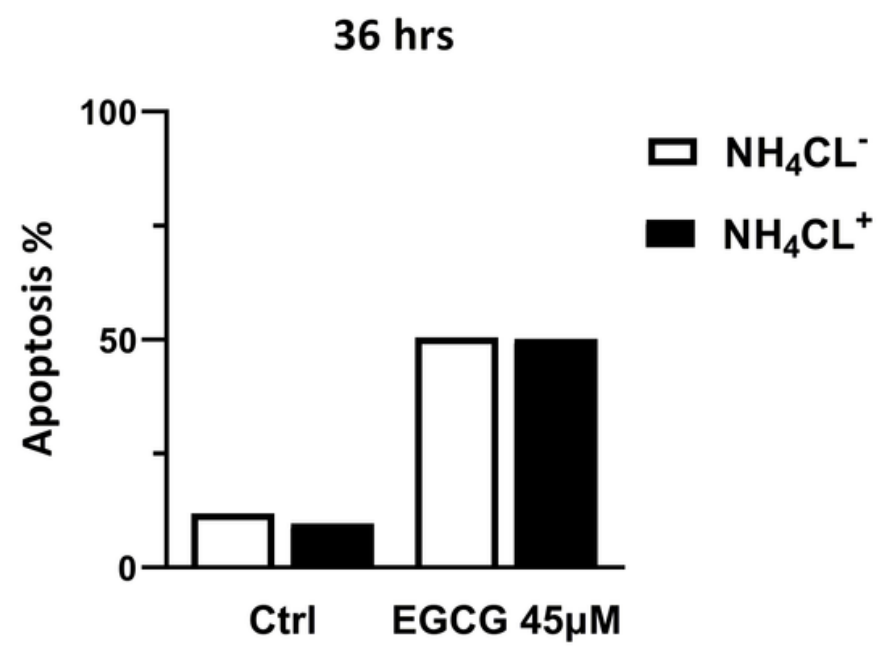

b

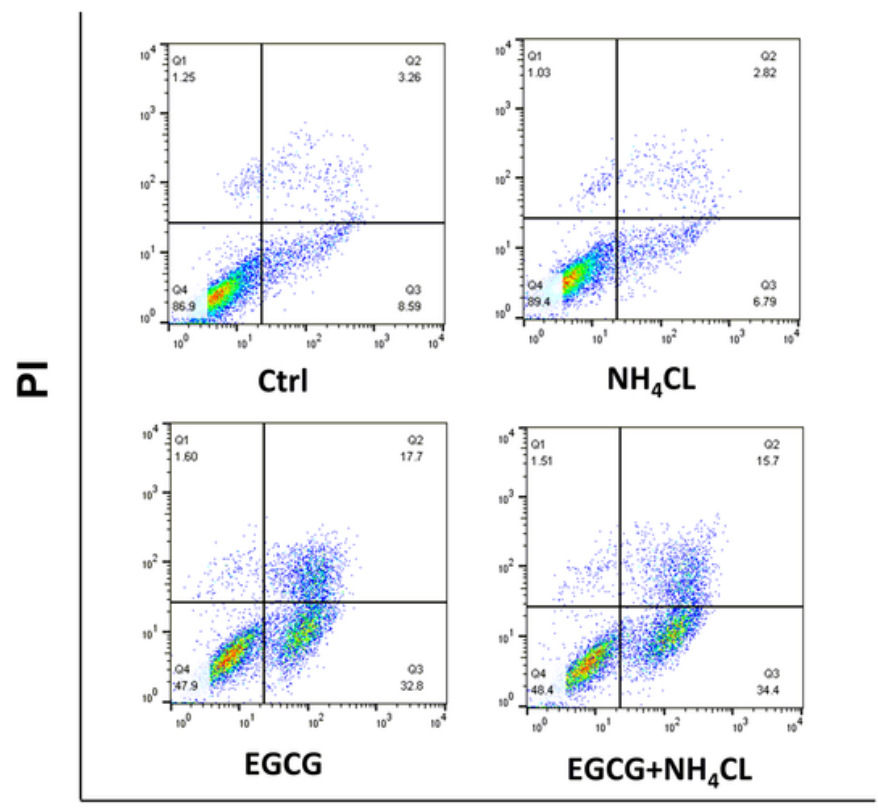

FITC-Annexin V

\section{Figure 5}

The effect of EGCG on apoptosis in NALM- 6 cells in the presence and absence of NH4CL as an autophagy inhibitor Cells were incubated with EGCG $45 \mu \mathrm{M}$ for 36 hours in the presence and absence of $\mathrm{NH} 4 \mathrm{CL} 10 \mathrm{mM}$ in the last 12 hours. (A) Data represented the apoptotic cell death in the presence and absence of autophagy inhibitor. (B) Depicted, using a BD FACS caliber flow cytometer. Annexin V-FITC- PIlocated in the left lower quadrant of the corresponding two-color FACS histogram assumed as live cells, and substantially Annexin V-FITC+ apoptotic cells located in the right quadrants considered as apoptotic cells.

\section{Supplementary Files}

This is a list of supplementary files associated with this preprint. Click to download.

- OnlineFigS1Gharechahiandetal..png 